\title{
A Case of Acute Myeloid Leukemia with Bilateral Leukemic Optic Nerve Infiltration
}

\author{
Yıldırım Rahşan ${ }^{1}$, Urlu Selin Merih², Sincan Gülden ${ }^{1, *}, K^{*}$ Kaban Göktürk ${ }^{2}$, Karaman Adem $^{3}$, Bilen Yusuf ${ }^{1}$ \\ ${ }^{1}$ Atatürk University, School of Medicine, Departments of Haematology, Erzurum, TURKEY \\ ${ }^{2}$ Atatürk University, School of Medicine, Departments of Internal Medicine, Erzurum, TURKEY \\ ${ }^{3}$ Atatürk University, School of Medicine, Departments of Radiology, Erzurum, TURKEY \\ *Corresponding author: guldensincan@gmail.com
}

Received January 27, 2015; Revised March 10, 2015; Accepted March 20, 2015

\begin{abstract}
Ocular involvement in patients with leukemia may be due to various reasons and it is characterized by various clinical symptoms. Ocular problems in patients who have acute myeloid leukaemia (AML) are commonly observed. Orbital and ocular lesions carry a poor prognosis in patients with acute myeloid leukemia. Direct invasion of the retina and choroid with the neoplastic cells is common, but the involvement of the optic nerve, uveal tract are relatively rare. Ocular symptoms include blurred vision and diplopia due to the involvement of optic nerves. This paper reports a 68 year old patient with AML. 5 azasitidin was initiated for treatment. By the second cycle, he complained of vision loss for right eye. These findings occured for left eye after three days. Optic nerve involvement was found with orbital magnetic resonance imaging with contrast. We report these patient because of rarity.
\end{abstract}

Keywords: acute myeloid leukemia, diplopia, optic nerve infiltration, vision loss

Cite This Article: Yıldırım Rahşan, Urlu Selin Merih, Sincan Gülden, Kaban Göktürk, Karaman Adem, and Bilen Yusuf, “A Case of Acute Myeloid Leukemia with Bilateral Leukemic Optic Nerve Infiltration.” American Journal of Medical Case Reports, vol. 3, no. 4 (2015): 111-112. doi: 10.12691/ajmcr-3-4-7.

\section{Introduction}

Acute myeloid leukemia is a cancer of the myeloid line of blood cells, characterized by the rapid growth of abnormal white blood cells that accumulate in the bone marrow and interfere with the production of normal blood cells. In a patient with acute myeloid leukemia two mechanisms may caused ocular involvoment; (1) direct leukaemic infiltration, (2) indirect involvement [1,2,3,4]. The direct leukaemic infiltration can show three patterns: orbital infiltration, anterior segment uveal infiltration and neuro-ophthalmic signs of central nervous system leukaemia that include optic nerve infiltration, cranial nerve palsies, and papilloedema. The secondary changes are the result of haematological abnormalities of leukaemia such as thrombocytopenia, hyperviscosity, anaemia, and immunosuppression. We report a patient who had bilatheral proptozis,exopthalmus, chemozis and vision loss due to bilatheral optic nerve infiltration.

\section{Case Report}

A 68 year old male patient was admitted to our department by fatigue, nause and dyspnea. His past medical history included of chronic obstructive lung disease, diabetes mellitus, hypertension and urinary bladder cancer (stage 0). Transurethral resection was performed to these patient. After, intravesical BCG was given ten years ago due to urinary bladder cancer. Patient was followed in remission. Family history of the patient was unremarkable.

On physcial examination his blood pressure was 100/70 $\mathrm{mmHg}$, pulse was 90 beats/min, no fever, there was a bilateral pulmonary rhonchi in lung and without any other significant findings.

Laboratory findings were as follows; level of hemoglobin was $9.2 \mathrm{gr} / \mathrm{dl}$, hematocrit $26.3 \%$, white cell count $7900 / \mathrm{mm}^{3}$, platelets $7000 / \mathrm{mm}^{3}$. Level of serum urea was $14 \mathrm{mg} / \mathrm{dl}$, creatinine $0.7 \mathrm{mg} / \mathrm{dl}$, sodium $135 \mathrm{mEq} / \mathrm{L}$, potassium $3.7 \mathrm{mEq} / \mathrm{L}$, uric acid $3.8 \mathrm{mg} / \mathrm{dl}$, C-reactive protein $2.9 \mathrm{mg} / \mathrm{l}$, aspartate amino transferaz $25 \mathrm{UI} / \mathrm{L}$, alanine amino transferaz $12 \mathrm{UI} / \mathrm{L}$, gamma glutamyl transferase $15 \mathrm{U} / \mathrm{L}$, alkaline phosphatase $49 \mathrm{U} / \mathrm{L}$, lactate dehydrogenase $610 \mathrm{U} / \mathrm{L}$, indirect biluribin $2.5 \mathrm{mg} / \mathrm{dl}$. There were $90 \%$ blasts in peripheral blood smear. A bone marrow aspiration revealed a $80 \%$ infiltration by blasts. CD 13, CD33 and myeloproxidase were positive in flow cytometry. We thought that M1 subtype of acute myeloid leukemia due to these findings and 5-azasitidine (75 $\mathrm{mg} / \mathrm{m}^{2} /$ day for seven days) was initiated. By the second cycle, he complained of vision loss for right eye. After three days these findings occured for left eye. On clinical examination, direct and indirect pupil reflects were nonreactive. The patient's vision was $1 / 10$ in right eye and 3/10 in left eye. Lumbar puncture was planned for central nervous system involvement. But that could not be performed due to bilateral optic disc edema. There were no signs of CNS involvement in cranial magnetic rezonans imaging. Optic nerve involvement was detected 
with orbital magnetic resonance imaging with contrast (Figure 1). There were blasts in the peripheral blood smear at the time of vision loss. During follow-up the patient leukemic cells was breakthrough in a couple of days and the patient died of second day of mechanical ventilation due to respiratory failure.

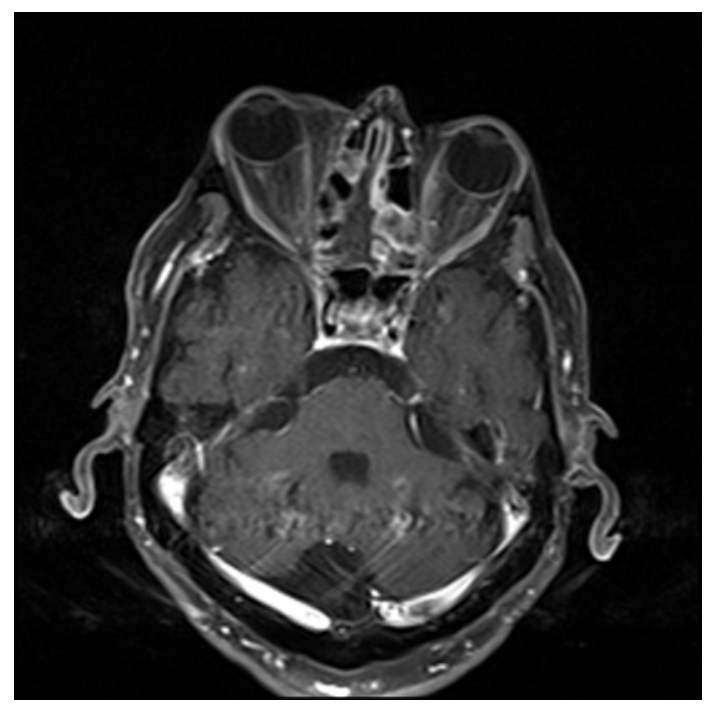

Figure 1.

\section{Discussion}

The frequency of ocular involvement varies according to the type of leukemia. It is seen more often in acute leukemia then chronic leukemia. The prevalence of ocular involvement in patients with leukemia between $9-90 \%$ in the literature $[5,6]$. Ocular involvement was seen in $82 \%$ of acute leukemias in $75 \%$ of chronic leukemia in postmortem autopsy report [7]. Ridgway et al has detected 9\% oculer involvoment in pediatric patients with acute myeloid leukemia. Schachat et all were detected 13-33\% of retinal findings in patients with acute myeloid leukemia [5]. Karesh et all have found \%53 fundus findings in patients with acute non-lymphoblastic leukemia [8].

Ocular infiltration with leukemia most commonly affects the retina and choroid [9]. Optic nerve involvement often associated with central nervous system involvement. But optic nerve may be directly infiltrated with leukemic cells without central nervous system involvement rarely. Kincaid and Green was detected optic nerve involvement $18 \%$ in acute leukemia and $16 \%$ in chronic leukemia [6]. There is involvement of the optic nerve without CNS involvoment in our case.

The presentation of optic nerve involvement in leukaemia represents a visual emergency. Because of optic nerve involvement may result in permanent blindness if not treated early start [10]. Oculer findings may be symptomatic or asymptomatic in patients with acute myeloid leukemia. Blurred vision or sudden vision loss are the most common symptoms. Thus routine eye examination should be performed in all patients with leukemia. Intrathecal injections of chemotherapeutic drugs including methotrexate, cytarabine and prednisolone may be given for treatment of optic nerve involvoment. Intratechal chemotheraphy was planned to our case for optic nerve involvement. But that could not be performed due to bilateral optic disc edema. Systemic chemotheraphy has effect on the optic nerve involvoment. In addition; focal irradiation is effective by reducing the leukaemic cell in the optic canal and this allows the cytotoxic drugs in the CSF to attack the neoplastic cells. Radiotherapy for optic nerve involvement could not be performed because the patient has still on chemothreaphy and was not on hematologic remission.

Optic nerve involvoment is more common in patients with acute leukemia and lymphoid malignancies than chronic leukemia. Optic nerve involvement is frequently seen in patients with relapsed and it is frequently associated with bone marrow or CNS involvement. In addition; it may be seen in patients with relapsed in the initial place [10]. There were blasts in the peripheral blood smear at the time of vision loss in our case.

Ophthalmic findings which depends on leukemic infiltration is considered as a poor prognostic indicator. Ophthalmic manifestations were observed at the time of blasts in the peripheral blood smear in our case. Elderly and the presence of other comorbidities has led to the worsening of prognosis in our patient.

\section{Conclusion}

Optic nerve involvement is the cause of significant morbidity and mortality in patients with leukemia and ophthalmic assessment should be performed in these patients. Therefore, it is important to consider an ophthalmic evaluation at the time of diagnosis of leukaemia in adults and children.

\section{Conflict of Interest}

We disclose financial interest in the equipment and disclose absence of commercial or propriety interest.

\section{References}

[1] Sharma T, Grewal J, Gupta S. Ophthalmic manifestations of acute leukaemias the ophthalmologist's role. Eye. 18. 663-672. 2004.

[2] Macintyre E, Flandrin G. Biological classification of acute leukemias: federalization or centralization? Leukemia. 9. 21522154. 1995.

[3] Leonardy NJ, Rupani M, Dent G, K. K. Gordon. Analysis of 135 autopsy eyes for ocular involvoment in leukemia. Am J Opthalmol. 109. 436-444. 1990

[4] Woei-A-Jin S; Ypma P; van den Biesen P. Bilateral optic nerve infiltration in a patient with acute myeloid leukaemia. $\mathrm{Br} J$ Haematol. 153 (1). 2. 2011.

[5] Schachat AP, Markowitz JA, Guyer DR, Burke P.J, Karp J.E, Graham M.L. Opthalmic manifestations of leukemia. Arch Ophthalmol. 107. 697-700. 1989.

[6] Lisa S, Mtevenina M.G, Nicholas J.V. Bilateral optic nerve infiltration in central nervous system leukemia American Journal of Ophthalmology. 135 (1). 94-96. 2003.

[7] Kincaid MC, Green WR. Ocular and orbital involvoment in leukemia. Surv Ophthalmol 27. 211-232. 1983.

[8] Karesj JW, Goldman EJ, Reck K, Kelman S.E, Lee E.J, Schiffer C.A. A prospective ophthalmic evaluation of patients with acute myeloid leukemia: correlation of ocular and hematologic findings. J Clin Oncol. 7 (10). 1528-1532. 1989.

[9] Rosenthal AR. Ocular manifestation of leukemia: A review. Ophthalmology. 90. 899-905. 1983.

[10] Schwartz CL, Miller NR, Wharam MD, Leventhal B.G. The optic nerve as the site of initial relapse in childhood acute lymphoblastic leukemia. Cancer. 63. 1616-1620. 1989. 